\title{
Order of stimulus presentation modulates interference in Stroop matching tasks: a reaction time study
}

\author{
Ariane Leão Caldas \\ Isabel de Paula Antunes David \\ Paula Martins Portes \\ Anna Carolina de Almeida Portugal \\ Walter Machado-Pinheiro' \\ Universidade Federal Fluminese, Niterói - RJ - Brasil
}

\begin{abstract}
In the classic Stroop effect, the time spent to name the color of an incongruent stimulus (GREEN in blue) is longer than the time necessary to name the color of a congruent stimulus (BLUE in blue). In the "Stroop matching task", volunteers are instructed to compare attributes of two stimuli, in which one of them is necessarily a Stroop stimulus. Our aim was to investigate whether the order of stimulus presentation can explain some contradictory results and reveal the imposition of high-order cognitive resources in conflict resolution. Our results confirmed that the strategy adopted in the task depended on the order in which stimuli were presented. In the "Stroop-Bar" order, using the interval between stimuli to solve the conflict inherent to the Stroop stimulus is possible, which is otherwise not possible in the "Bar-Stroop" order. However, these strategies cannot explain the discrepancy in the results reported in the literature.
\end{abstract}

Keywords: attention; reaction time; Stroop; executive function; conflict resolution.

\section{ORDEM DE APRESENTAÇÃO DE ESTÍMULOS MODULA INTERFERÊNCIAS EM TESTES STROOP-PAREADO: UM ESTUDO DE TEMPO DE REAÇÃO}

\begin{abstract}
Resumo: No teste Stroop clássico, o tempo gasto para nomear a cor de um estímulo incongruente (VERDE em azul) é maior que o necessário para nomear a cor de um estímulo congruente (AZUL em azul). No teste Stroop-Pareado (Stroop matching task), voluntários são instruídos a comparar atributos de dois estímulos, sendo um deles, necessariamente, um estímulo Stroop. Nosso objetivo foi investigar se a ordem de apresentação dos estímulos pode explicar resultados contraditórios e revelar a imposição de recursos de alta ordem na solução de conflitos. Nossos resultados confirmam que a estratégia adotada para desempenhar a tarefa depende da ordem na qual os estímulos foram apresentados. Na ordem "Stroop-Barra", é possível usar o intervalo entre os estímulos para solucionar o conflito inerente ao estímulo Stroop, o que não é possível na ordem "Barra-Stroop". No entanto, essas estratégias não conseguem explicar a discrepância de resultados observados na literatura.
\end{abstract}

Palavras-chave: atenção; tempo de reação; Stroop; função executiva; solução de conflito.

\section{ORDEN DE PRESENTACIÓN DE ESTÍMULOS MODULA INTERFERENCIAS EN TESTES STROOP-PAREADO: UN ESTUDIO DE TIEMPO DE REACCIÓN}

Resumen: En la tarea Stroop clásica, el tiempo utilizado para nombrar el color de un estímulo incongruente (VERDE en azul) es más grande que lo necesario para nombrar

1 Endereço para correspondência: Walter Machado-Pinheiro, Departamento Interdisciplinar de Rio das Ostras, Instituto de Humanidades e Saúde da Universidade Federal Fluminense/campus Rio das Ostras, Rua Recife, s/n, Jardim Bela Vista, Rio das Ostras - RJ - Brasil. CEP: 28890-000. E-mail: walter@vm.uff.br. 
el color de un estímulo congruente (AZUL en azul). En una tarea Stroop de comparación (Stroop matching task), voluntarios son instruidos a comparar atributos de dos estímulos, uno de ellos siendo necesariamente un estímulo Stroop. Nuestro objetivo fue investigar si el orden de presentación de los estímulos puede explicar algunos resultados contradictorios y revelar la imposición de recursos de alto orden en la solución de conflictos. Nuestros resultados confirman que la estrategia adoptada en la tarea depende del orden en el cual los estímulos fueran presentados. En el orden "Stroop-Barra" es posible utilizar el intervalo entre los estímulos para solucionar el conflicto inherente al estímulo Stroop, lo que no es posible en el orden "Barra-Stroop". Sin embargo, esas estrategias no consiguen explicar la discrepancia de los resultados observados en la literatura.

Palabras clave: atención; tiempo de reacción; Stroop; función ejecutiva; solución de conflicto.

The complex environment in which we live makes distinguishing relevant from irrelevant information necessary. The Stroop task (Stroop, 1935) is widely used to study the competition between task-relevant and task-irrelevant contingencies. The Stroop effect relies on the observation that volunteers spend more time naming the color of ink of incongruent color-words (e.g., the word "blue" in red ink) than congruent color-words (e.g., the word "blue" in blue ink) or neutral ones (e.g., a row of colored Xs). Since the original study by Stroop (1935), many variations of the paradigm have been created. Among the several variations, a particularly interesting one is the socalled "Stroop matching task", first proposed by Treisman and Fearnley (1969). In this task, a congruent or incongruent Stroop stimulus is presented with a colored bar, a row of colored Xs, or another color-word printed in a neutral color. The participants are instructed to match the relevant attribute of the Stroop stimulus to the other stimulus (e.g., compare the word of the Stroop stimulus with the color of a colored bar). Thus, after Treisman and Fearnley (1969), the Stroop matching task has been widely used in the literature (Caldas, Machado-Pinheiro, Souza, Motta-Ribeiro, \& David, 2012; David et al., 2011; Durgin, 2003; Dyer, 1973; Goldfarb \& Henik, 2006; Luo, 1999; Machado-Pinheiro et al., 2010). Notably, interference (i.e., slower responses for incongruent Stroop stimuli than for congruent Stroop stimuli) has been consistently found only when between-feature matches are required such as in color-to-word or word-to-color comparisons, and not for within-feature matching when color-to-color or word-to-word comparisons were necessary (Luo, 1999; Sugg \& McDonald, 1994; Treisman \& Fearnley, 1969). This peculiarity supports the translational account of the Stroop effect, which states that interference occurs when translating between the internal code of the relevant attribute to another code is necessary before response execution (Glaser \& Glaser, 1989; Virzi \& Egeth, 1985) and this step is only required in between-feature matches.

The use of Stroop matching tasks has allowed important advances in relation to the origin and solution of Stroop-like interference. However, some important issues still remain unclear because of discrepancies reported in the literature. Luo (1999) used a condition called "meaning decision task", in which the participants were instructed to compare the surface color of a colored bar with the meaning (word) of the Stroop stimulus. The two stimuli were presented simultaneously, above and below 
the fixation point, respectively, and the subjects had to press one of two keys to indicate whether the response of this match was the "same" or "different". According to the stimuli and their combinations, five conditions could be generated (Figure 1A). However, in his analysis, Luo (1999) grouped conditions 3 and 5 together and called them "mismatch" - in which the color of the bar and the color of the Stroop stimulus (i.e., the irrelevant attribute) did not match. He showed that for both "same" and "different" responses, the "mismatch" conditions (condition 2/ "same" and conditions 3+5/ "different") were slower than the "match" conditions (condition 1/ "same" and condition 4/ "different"). In other words, reaction times were shorter when the surface colors of both stimuli were equal. Luo (1999) interpreted these results based on a semantic competition hypothesis, which states that interference is attributable to the simultaneous activation of two different representations of color in a semantic analyzer when the stimuli have different color surfaces ("mismatch"). When the two stimuli have the same color surfaces ("match"), only one representation of color is generated, resulting in no competition or interference.

The methodology that Luo (1999) used to analyze his data was criticized by Goldfarb and Henik (2006). They called attention to the fact that in the "different/ mismatch" condition in Luo (1999), congruent (condition 3) and incongruent (condition 5) Stroop stimuli were pooled. Thus, in contrast to Luo (1999), Goldfarb and Henik (2006) did not group conditions 3 and 5, and all five conditions were analyzed separately (two for "same" responses and three for "different" responses). The results of the new analysis by Goldfarb and Henik (2006) did not change the pattern observed for "same" responses, in which condition 2 (Incongruent/Mismatch) still generated slower responses than condition 1 (Congruent/Match). However, the results obtained for "different" responses differed from Luo (1999). In Goldfarb and Henik (2006), the responses were slower for condition 3 (Congruent/Mismatch), and conditions 4 (Incongruent/Match) and 5 (Incongruent/Mismatch) did not differ from each other. According to the interpretation by Goldfarb and Henik (2006), the participants erroneously made irrelevant comparisons between the relevant and irrelevant attributes of the Stroop stimulus (word and surface color, respectively), and such erroneous comparisons generated an erroneous response code that interfered with response selection. Thus, congruent and incongruent Stroop stimuli would lead to "same" and "different" erroneous response codes, respectively. Conflict would occur when the Stroop stimulus was congruent but the correct response was "different", and when the Stroop stimulus was incongruent but the correct response was the "same". Because in these cases two conflicting response codes were generated at the same time, the authors proposed that conflict at the response level was another possible explanation for the Stroop matching tasks effect, although they did not discard the possibility that nonresponse (semantic) conflict could also be involved.

An important aspect of Luo (1999) and Goldfarb and Henik (2006) is that the colored bar in their paradigms was always presented above the fixation point, and the Stroop stimulus was always presented below the fixation point. In another study, in a task called "word-to-color", Dyer (1973) instructed the volunteers to compare the 
word of the Stroop stimulus that was presented above the fixation point with the color of a colored bar that was presented below the fixation point. Dyer (1973) actually used a row of colored Xs, which is similar to a colored bar because neither present any kind of conflict. Compared with the data reported by Goldfarb and Henik (2006), Dyer's (1973) results presented the same pattern with regard to the "same" responses (i.e., the Incongruent/Mismatch condition generated slower responses than the Congruent/ Match condition). However, the results for "different" responses were in the opposite direction. Responses in condition 3 (Congruent/Mismatch) were the slowest in Goldfarb and Henik (2006), whereas Dyer (1973) reported that responses in the Congruent/ Mismatch condition were faster than in conditions 4 (Incongruent/Match) and 5 (Incongruent/Mismatch). As shown in Figure 1A, the conditions used by Goldfarb and Henik (2006) and Dyer (1973) were the same, the only difference was the order of stimulus presentation: Goldfarb and Henik (2006) used the "Bar-Stroop" order (i.e., the colored bar above the fixation point and the Stroop stimulus below the fixation point), whereas Dyer (1973) used the "Stroop-Bar" order (i.e., the Stroop stimulus above the fixation point and the colored bar below the fixation point).

In the present study, the participants performed the Stroop matching tasks in both of these orders ("Bar-Stroop" and "Stroop-Bar") in an attempt to determine whether the discrepancies between Goldfarb and Henik (2006) and Dyer (1973) were attributable to the different strategies adopted by the participants when they were presented with different stimulus orders. We also extended our protocol in one important respect. To evaluate the imposition of high-order cognitive control by the participants, we manipulated stimulus onset asynchrony (SOA) between the two stimuli. Thus, in addition to the simultaneous presentation adopted by these authors (i.e., SOA $0 \mathrm{~ms}$ ), we also introduced time intervals of 200 and 800 ms between stimuli in both order conditions to investigate the time course of the imposition of cognitive control. An important consideration is the relevant aspect of both orders. In the "Stroop-Bar" order, the Stroop stimulus appears first, so the participants can use the time interval to solve the conflict between both attributes of an incongruent Stroop stimulus (color and word) before any motor response is required. In the "Bar-Stroop" order, the interval occurs after the appearance of the bar, thus before the Stroop stimulus. Because no conflict exists with a colored bar, the interval cannot be used in the "Bar-Stroop" order to solve any conflict that is inherent to an incongruent Stroop stimulus before the manual response is required. Therefore, we hypothesize that the "Stroop-Bar" order will be more favored by the introduction of time intervals between stimuli than the "Bar-Stroop" order.

\section{Methods}

\section{Participants}

Twenty-four undergraduate students (10 men, 14 women) from Fluminense Federal University, aged 19-29 years (mean, $20.9 \pm 2.1$ years), volunteered to participate in the study. All of the participants had normal or corrected-to-normal visual acuity and normal color vision. Handedness was previously assessed and only one of the participants was left-handed. They were naive to the goals of the study. All of the procedures were 
approved by the local Research Ethics Committee, and written informed consent was obtained from the participants before the study.

\section{Apparatus}

The experiment was conducted in a sound-attenuated room under dim ambient light. The participants sat in front of an LCD monitor with their head resting on a forehead/chin support approximately $57 \mathrm{~cm}$ from the screen. A computer that ran E-Prime v1.2 software (Psychological Software Tools Inc.) timed the presentation of the stimuli and recorded key presses. A keyboard was placed on a table between the participant and the monitor, and the " 1 " and " $Z$ " served as response keys that were operated with the right and left index fingers, respectively.

\section{Stimuli and procedure}

Three ink colors and their names were used to generate the experimental stimuli: red green and blue. Each trial consisted of a colored bar $\left(0.9^{\circ} \times 5.4^{\circ}\right.$ of the visual angle) and a colored word $\left(0.9^{\circ} \times 0.9^{\circ}\right.$ for each letter $)$ in a congruent or incongruent ink color (Stroop stimulus [StS]; Figure 1B). Each trial began with a fixation point (FP; i.e., an empty circle) that was presented for 500-600 ms. The two stimuli then appeared simultaneously (SOA $0 \mathrm{~ms}$ ) or with SOA of 200 or $800 \mathrm{~ms}$ between them. Both stimuli remained on the screen until the emission of a response (or until $1500 \mathrm{~ms}$ elapsed), and a new trial began after an intertrial interval of 800 ms. The participants performed two experimental sessions on different days. In the "Bar-Stroop" session, the first stimulus (S1) was a colored bar that was positioned $1.5^{\circ}$ above the FP, and the second stimulus (S2) was a StS that was positioned $1.5^{\circ}$ below the FP. In the "Stroop-Bar" session, the order of the stimuli was reversed, in which S1 was a StS and S2 was a colored bar. In both sessions, the participants were instructed to match the color of the bar to the meaning of the word, regardless of the order of stimulus presentation, and press one of the two keys as soon as the stimuli appeared according to the match: "same" or "different" (Manual Reaction Time - MRT). Before each session, the participants received specific instructions and executed a short practice block (approximately 20 trials) under the supervision of the experimenter.

There were three variables: congruency, relationship, and response. The StS could be "congruent" (Cong - e.g., the word "red" in red ink) or "incongruent" (Incong - e.g., the word "red" in blue ink). The StS and bar could be "related" or "unrelated", depending on whether the bar and color-word were presented with the same surface color. For example, in conditions 1 and 4 (Figure 1B), the StS and bar had the same surface color and were "related" (Rel). In conditions 2, 3, and 5, the StS and bar had different surface colors and were "unrelated" (Unrel). The StS and bar could be the "same" or "different" (diff), depending on the matching required (i.e., whether the color of the bar matched or not to the word meaning). As shown in Figure 1B, there were two possible conditions for "same" responses: Cong/Rel (condition 1) and Incong/Unrel (condition 2). There were also three possible conditions for "diff" responses: Cong/Unrel (condition 3), Incong/Rel (condition 4), and Incong/Unrel (condition 5). 
Figure I. Summary of experimental conditions adopted in the present study and by other authors. (A) Conditions adopted by Luo (1999), Goldfarb and Henik (2006), and Dyer (1973). Luo (1999) pooled conditions 3 and 5, calling them "mismatch". Both Goldfarb and Henik (2006) and Dyer (1973) analyzed the five conditions separately. (B) Sequence of events and conditions adopted in both sessions in the present study: "Bar-Stroop" (left) and "Stroop-Bar" (right). Notice the similarity between the conditions in the present study (numbered I to 5) and those adopted in the other studies. For details, see text

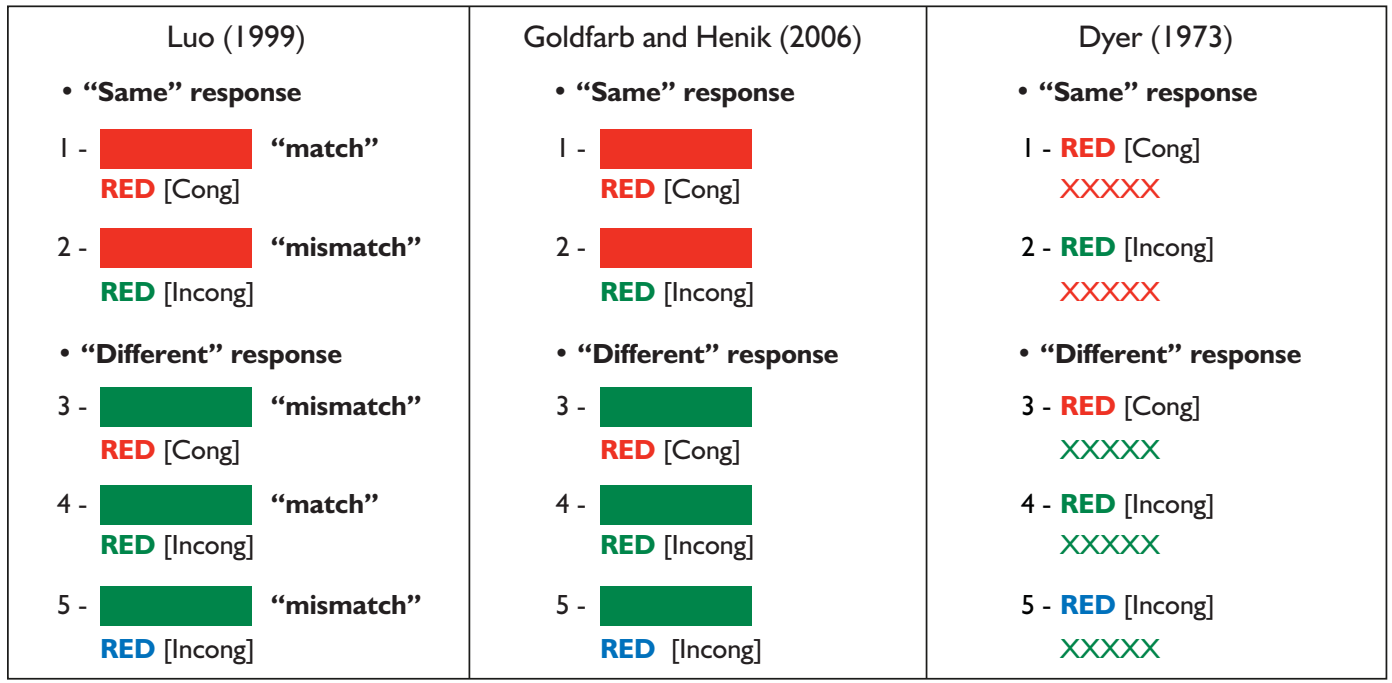

(A)

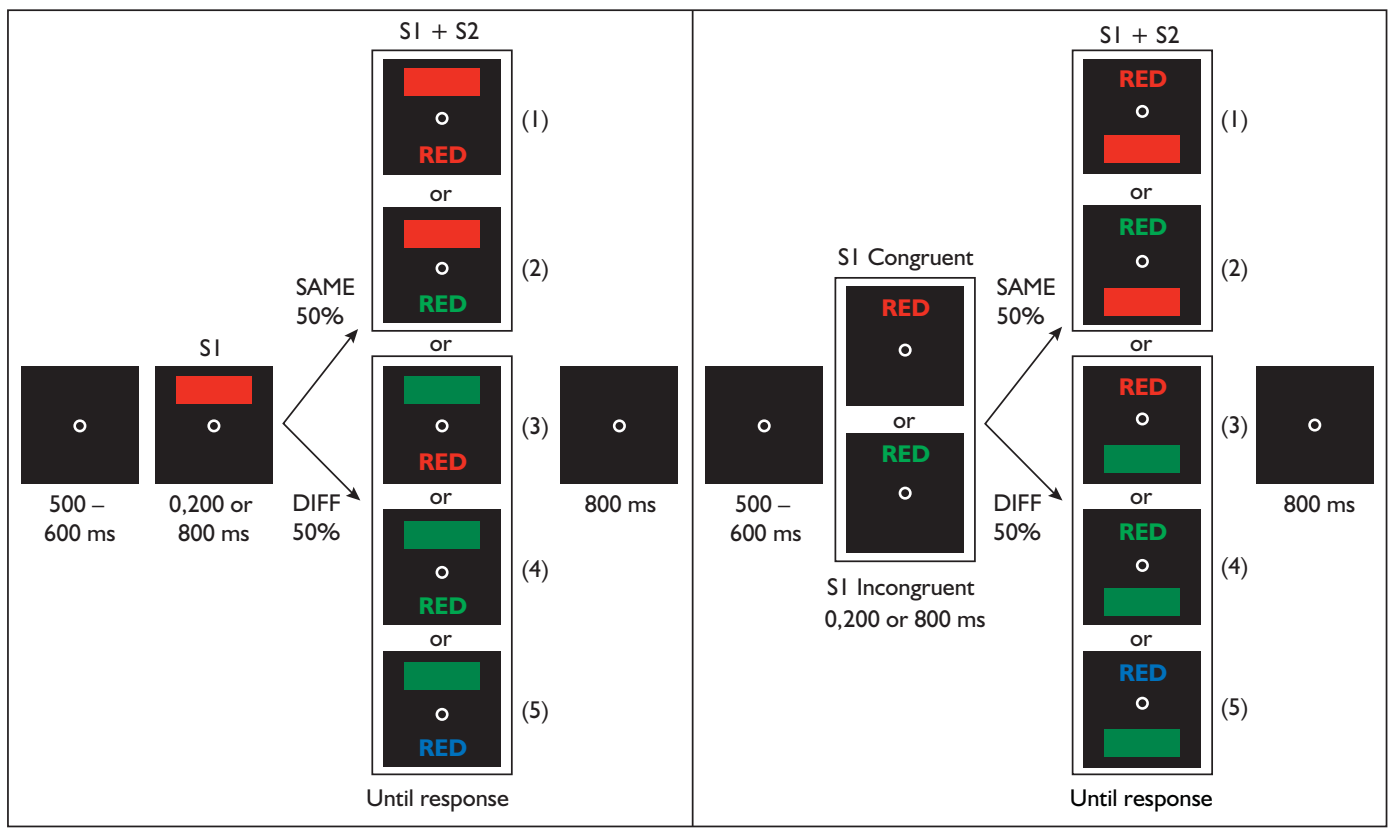

(B)

Source: Elaborated by authors. 
Each experimental session lasted approximately $25 \mathrm{~min}$ and consisted of 216 trials (108 trials for "same" responses and 108 trials for "different" responses) distributed in three blocks with 72 trials each. The participants were allowed to rest for a few minutes between blocks. The conditions and order of the blocks were randomized among subjects. For half of the subjects, the "1" key corresponded to the "same" response. For the other half, the " $Z$ " key corresponded to the "same" response. Likewise, half of the subjects performed the "Stroop-Bar" session on the first day, and the other half performed the "Bar-Stroop" session on the first day.

\section{Data analysis}

We conducted two separate repeated-measures analyses of variance (Anovas), one for each experimental session ("Bar-Stroop" and "Stroop-Bar"), with Condition (Same/ Cong/Rel, Same/Incong/Unrel, Diff/Cong/Unrel, Diff/Incong/Rel, and Diff/Incong/Unrel) and SOA $(0,200$, and $800 \mathrm{~ms})$ as the within-subjects factors for correct MRT data. When appropriate, the Newman-Keuls post hoc test was also performed, and Greenhouse-Geisser epsilon $(\varepsilon)$ correction for nonsphericity was applied. Original $d f$ values and corrected $p$ values are reported. Because errors were rare and no variance was found in some of the conditions, we could not apply conventional statistical analyses, and only $t$-tests were used to analyze these data. The alpha level adopted for statistical significance was $a=0.05$.

\section{Results}

\section{Error analysis}

The overall mean percentage of errors among all of the participants was 3.98\% (413 errors in 10,368 trials). Errors were more frequent during "Bar-Stroop" session (232) than during the "Stroop-Bar" session (181) - paired $t$-test, $p=0.016$. Most of these errors were incorrect key presses $(390-94.4 \%)$, and the remainder corresponded to slow responses $(23-5.6 \%)$, i.e., when MRTs were longer than 1,500 ms. For both sessions, paired $t$-tests revealed that errors were more frequent in the Incong/Unrel condition for "same" responses and more frequent in the Cong/Unrel condition for "different" responses $(p<0.05)$.

\section{Reaction time analysis}

"Bar-Stroop" session

The Anova revealed a main effect of Condition $[F(4,92)=67.07, p<0.001, \varepsilon=0.65]$, and the post hoc analysis revealed that MRTs for "same" responses were slower in the Incong/Unrel condition than in the Cong/Rel condition (632 ms and $545 \mathrm{~ms}$, respectively; $p<0.001)$. For "diff" responses, the Cong/Unrel condition $(720 \mathrm{~ms})$ differed significantly from the Incong/Rel condition (666 ms, $p<0.001)$ and Incong/Unrel condition (681 ms, $p=0.001)$. The difference between the two incongruent conditions was not significant $(p>0.05)$. The Anova revealed a main effect of SOA $[F(2,46)=91.34, p<0.001, \varepsilon=0.70]$, with MRTs decreasing as SOA increased $(780 \mathrm{~ms}, 619 \mathrm{~ms}$, and $547 \mathrm{~ms}$ at SOA 0, 200, and 
$800 \mathrm{~ms}$, respectively; $p<0.001$ for all comparisons). Graphic 1 shows the significant interaction between Condition and SOA $[F(8,184)=9.45, p<0.001, \varepsilon=0.66]$. For "same" responses, MRTs in the Incong/Unrel condition were slower than in the Cong/Rel condition at the three SOAs: (i) SOA 0 ms (784 ms and $648 \mathrm{~ms}$ ), (ii) SOA $200 \mathrm{~ms}$ (593 ms and $518 \mathrm{~ms}$ ), and (iii) SOA $800 \mathrm{~ms}$ (518 ms and $467 \mathrm{~ms} ; p<0.001$ for all comparisons). For "diff" responses, at SOA 0 ms, all of the conditions differed (894 ms, 764 ms, and 808 $\mathrm{ms}$ for the Cong/Unrel, Incong/Rel, and Incong/Unrel conditions, respectively; $p \leq 0.006$ for all comparisons). At SOA $200 \mathrm{~ms}$, the Cong/Unrel condition (691 ms) differed significantly from the Incong/Rel (641 ms, $p=0.003)$ and Incong/Unrel (651 ms, $p=0.006)$ conditions, but the difference between the two incongruent conditions was not significant $(p>0.05)$. Finally, at SOA $800 \mathrm{~ms}$, no differences were found among conditions (573 ms, 592 ms, and 582 ms for the Cong/Unrel, Incong/Rel, and Incong/Unrel conditions, respectively; $p>0.05$ for all comparisons).

Grafic I. Manual reaction times (in $\mathrm{ms}$ ) for the five adopted conditions at SOA 0, 200, and $800 \mathrm{~ms}$ in the "Bar-Stroop" session. The asterisks represent statistically significant differences $(p<0.05)$, and the bars indicate the standard error of the mean

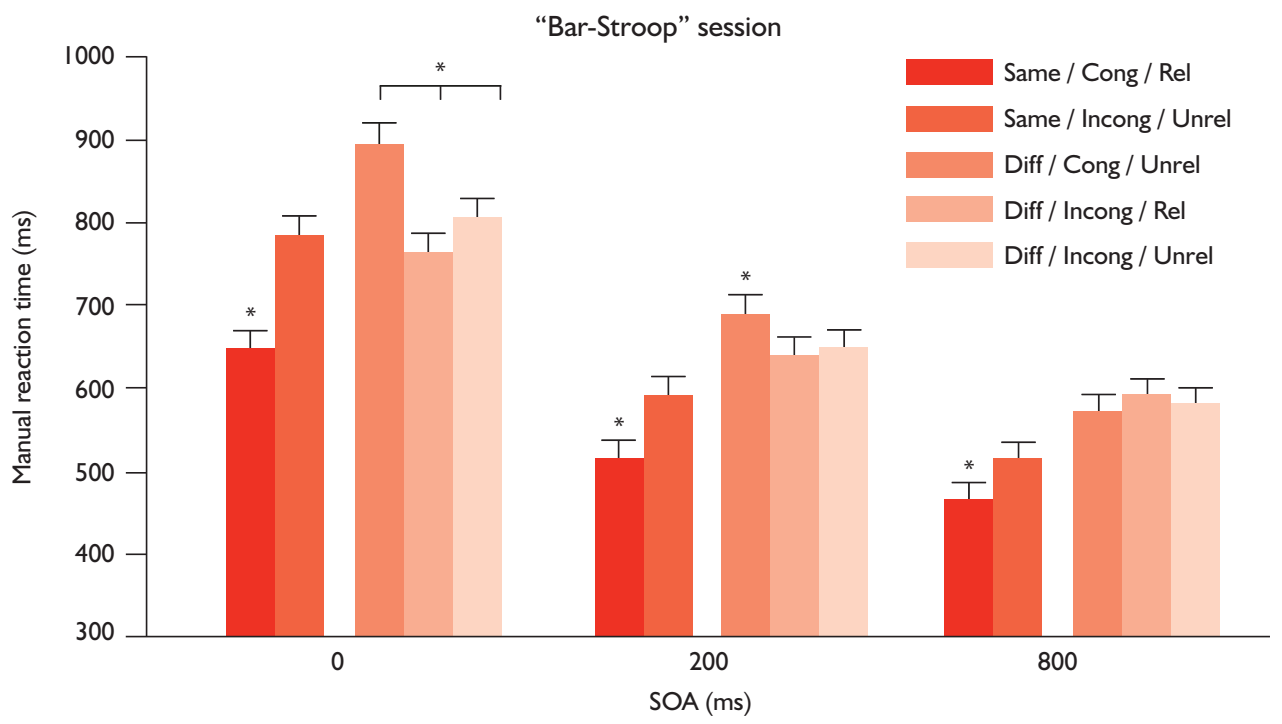

Source: Elaborated by authors.

\section{"Stroop-Bar" session}

The Anova revealed a main effect of Condition $[F(4,92)=45.53, p<0.001, \varepsilon=0.69]$ and the post hoc analysis revealed that MRTs for "same" responses were slower in the Incong/Unrel condition (573 ms) than in the Cong/Rel condition (513 ms, $p<0.001)$. For "diff" responses, the Cong/Unrel condition $(652 \mathrm{~ms})$ differed significantly from the Incong/Rel $(602 \mathrm{~ms}, p<0.001)$ and Incong/Unrel $(604 \mathrm{~ms}, p<0.001)$ conditions. The difference between the two incongruent conditions was not significant $(p>0.05)$. 
The Anova revealed a main effect of SOA $[F(2,46)=128.57, p<0.001, \varepsilon=0.94]$ with MRTs decreasing as SOA increased (724 ms, $553 \mathrm{~ms}$, and $489 \mathrm{~ms}$ at SOAs of 0, 200, and $800 \mathrm{~ms}$, respectively; $p<0.001$ for all comparisons). Graphic 2 shows the significant interaction between Condition and SOA $[F(8,184)=11.80, p<0.001, \varepsilon=0.62]$. For "same" responses, MRTs in the Incong/Unrel condition were slower than in the Cong/ Rel condition at SOA 0 ms (724 ms and $619 \mathrm{~ms}, p<0.001)$ and SOA $200 \mathrm{~ms}$ (550 ms and $477 \mathrm{~ms}, p<0.001$ ). At SOA $800 \mathrm{~ms}$, these conditions did not differ (445 ms and $442 \mathrm{~ms}$, respectively; $p>0.05$ ). For "diff" responses, at SOA $0 \mathrm{~ms}$, all of the conditions differed (820 ms, 707 ms, and 748 ms for the Cong/Unrel, Incong/Rel, and Incong/Unrel conditions, respectively; $p \leq 0.003$ for all comparisons). At SOA $200 \mathrm{~ms}$, the Cong/Unrel condition (619 ms) differed significantly from the Incong/Rel (566 ms, $p<0.001)$ and Incong/Unrel (555 ms, $p<0.001$ ) conditions, but the difference between the two incongruent conditions was not significant ( $p>0.05)$. At SOA $800 \mathrm{~ms}$, no difference was found among conditions (517 ms, 534 ms, and 509 ms for the Cong/Unrel, Incong/ Rel, and Incong/Unrel conditions, respectively; $p>0.05$ for all comparisons).

Therefore, as shown Graphics 1 and 2, despite the fact that MRTs were longer in the "Bar-Stroop" session than in the "Stroop-Bar" session (648 ms vs. 589 ms, $p<0.001$, paired $t$-test), a similar pattern of results was obtained in both sessions. The only difference was that the Same/Cong/Rel and Same/Incong/Unrel conditions at SOA 800 in the "Bar-Stroop" session differed significantly, but this difference was not found in the "Stroop-Bar" session.

Grafic 2. Manual reaction times (in $\mathrm{ms}$ ) for the five adopted conditions at SOA 0, 200, and $800 \mathrm{~ms}$ in the "Stroop-Bar" session. The asterisks represent statistically significant differences $(p<0.05)$, and the bars indicate the standard error of the mean

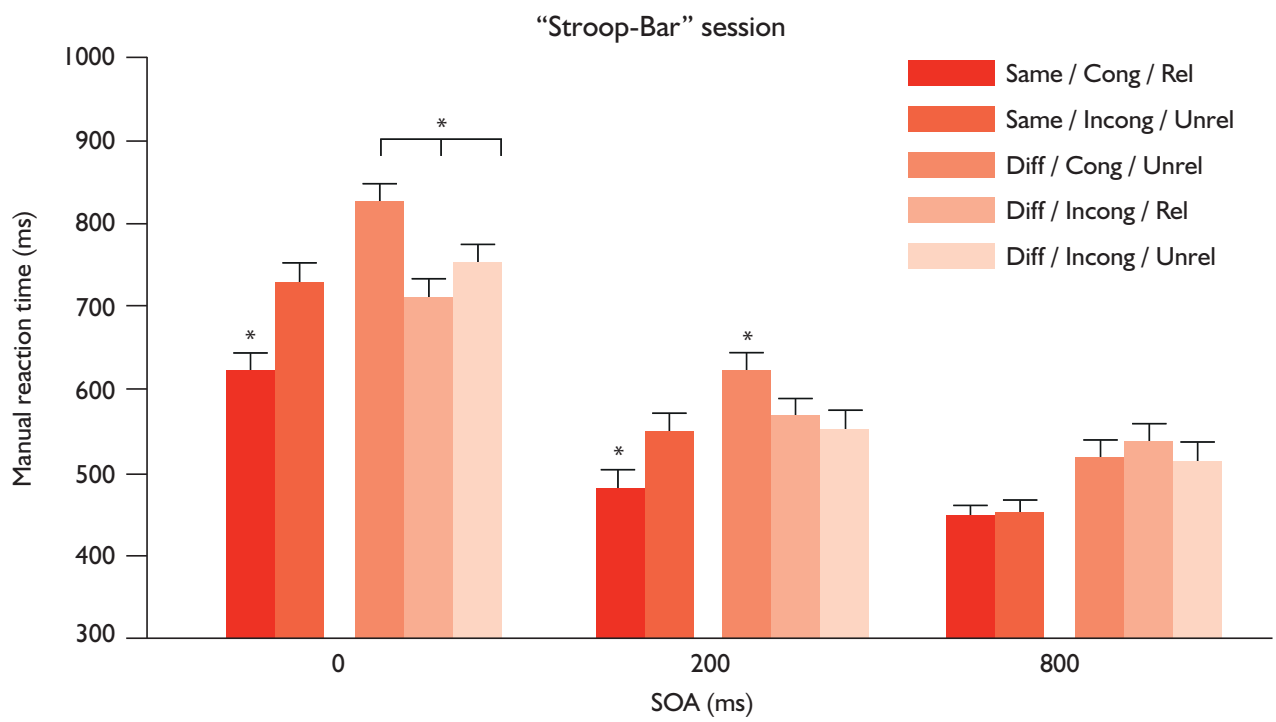

Source: Elaborated by authors. 


\section{Discussion}

We conducted a Stroop matching tasks with different orders of stimulus presentation in an attempt to explain the contradictory results obtained by Goldfarb and Henik (2006) and Dyer (1973). With this goal, we repeated the protocols applied by both studies using two different sessions: "Bar-Stroop" - similar to that applied by Goldfarb and Henik (2006) - and "Stroop-Bar" - similar to that applied by Dyer (1973). The results we obtained in both sessions at SOA $0 \mathrm{~ms}$ (the only interval used by those authors) corroborated the results reported by Goldfarb and Henik (2006), in which MRTs were longer in the Same/Incong/Unrel and in the Diff/Cong/Unrel conditions. Therefore, the response conflict theory used by Goldfarb and Henik (2006) to explain their results can also be applied to our findings. It states that MRTs are slower when concurrent response activation occurs (even implicitly) because of task demands. This theory has already been supported by others who used different physiological techniques (Duncan-Johnson \& Kopell, 1981; Ilan \& Polich, 1999; MacLeod \& MacDonald, 2000). In a previous study, our group demonstrated that both response and nonresponse conflicts are responsible for the results observed in a Stroop matching task (Caldas et al., 2012). To our knowledge, the controversial results reported by Dyer (1973) in his "word-to-color" task have not been replicated in the literature. Actually, in the same paper Dyer (1973) also used a "color-to-word" task and found that, as expected, the Diff/Cong/Unrel condition was slower than the Diff/Incong/Rel and Diff/Incong/Unrel conditions. Thus, the reason for this discrepancy remains unclear.

If we had only used SOA 0 ms in the present study, just as adopted by the others, then our conclusion would be that the order of stimulus presentation does not interfere with the required task because the pattern of results was very similar in both orders. Again, at 200 ms, the pattern obtained for both tasks did not differ. Importantly, however, our premise was confirmed when the data obtained at SOA 800 ms were analyzed. It allowed us to observe the imposition of high-order cognitive control by the participants while they performed both sessions. In the "Bar-Stroop" session, the difference between the Same/Cong and Same/Incong conditions was significant at all of the SOAs used, even 800 ms. However, in the "Stroop-Bar" session, this difference disappeared at $800 \mathrm{~ms}$. These results indicate that at SOA $800 \mathrm{~ms}$, attentional resources were recruited to resolve the conflict between the attributes of the incongruent StS, thus negating the interference caused by the irrelevant color in the task. Cognitive control associated with the recruitment and application of attentional resources to minimize the effects of distractive attributes is a characteristic inherent to the attentional executive system. This cognitive control is crucial when stimulus conflicts are present and the correct execution of a task requires the inhibition of distractive information (Miller \& Cohen, 2001; Posner \& Digirolamo, 1998; Banich, 2009). Indeed, neuroimaging studies have consistently demonstrated that brain areas that are related to the executive attentional system, particularly the prefrontal dorsolateral and anterior cingulate cortices, are active during situations of stimulus conflict (MacDonald, Cohen, Stenger, \& Cater, 2000; MacLeod \& MacDonald, 2000; Milham et al., 2001). Thus, our 
hypothesis that volunteers would adopt different strategies when presented with stimuli in different orders was confirmed. In general, the "Stroop-Bar" session presented less errors and faster MRTs than the "Bar-Stroop" session, suggesting that the former is an easier task, likely because of the imposition of cognitive control during SOA. We conclude that when the StS appears above the FP, volunteers begin solving the conflict inherent to it and then proceed with the comparison to the bar's color. At SOA $800 \mathrm{~ms}$, the distractive attribute of the StS was abolished. This strategy is not possible when the bar is presented first because no conflict occurs that needs to be resolved with such a stimulus.

In summary, the present results confirm that the strategy adopted by the volunteers depended on the order that the stimuli were presented. In the "Stroop-Bar" session, the interval between stimuli was used to solve the conflict inherent to Stroop stimulus, which was not possible in the "Bar-Stroop" session. However, this cannot explain the controversial results found in the literature, especially those reported by Dyer (1973).

\section{References}

Banich, M. T. (2009). Executive function: the search for an integrated account. Current Directions in Psychological Science, 18(2), 89-94.

Caldas, A. L., Machado-Pinheiro, W., Souza, L. B., Motta-Ribeiro, G. C., \& David, I. A. (2012). The Stroop matching task presents conflict at both the response and nonresponse levels: an event-related potential and electromyography study. Psychophysiology, 49, 1215-1224.

David, I. A., Volchan, E., Vila, J., Keil, A., de Oliveira, L., Faria-Junior, A. J. P., Perakakis, P., Dias, E. C., Mocaiber, I., Pereira, M. G., \& Machado-Pinheiro, W. (2011). Stroop matching task: role of feature selection and temporal modulation. Experimental Brain Research, 208(4), 595-605.

Duncan-Johnson, C. C., \& Kopell, B. S. (1981). The Stroop effect: brain potentials localize the source of interference. Science, 214, 938-940.

Durgin, F. H. (2003). Translation and competition among internal representations in a reverse Stroop effect. Perception and Psychophysics, 65(3), 367-378.

Dyer, F. N. (1973). Same and different judgments for word-color pairs with "irrelevant" words or colors: evidence for word-code comparisons. Journal of Experimental Psychology, 98(1), 102-108.

Glaser, W. R., \& Glaser, M. O. (1989). Context effects in Stroop-like word and picture processing. Journal of Experimental Psychology: General, 118(1), 13-42.

Goldfarb, L., \& Henik, A. (2006). New data analysis of the Stroop matching task calls for a reevaluation of theory. Psychological Science, 17(2), 96-100. 
Ilan, A. B., \& Polich, J. (1999). P300 and response time from a manual Stroop task. Clinical Neurophysiology, 110, 367-373.

Luo, C. R. (1999). Semantic competition as the basis of Stroop interference: evidence from color-word matching tasks. Psychological Science, 10, 35-40.

MacDonald , A. W., Cohen, J. D., Stenger, V. A., \& Cater, C. S. (2000). Dissociating the role of the dorsolateral prefrontal and anterior cingulate cortex in cognitive control. Science, 288(9), 1835-1838.

Machado-Pinheiro, W., Volchan, E., Vila, J., Dias, E. C., Alfradique, I., Oliveira, L., Pereira, M. G., \& David, I. A. (2010). Role of attention and translation in conflict resolution: implications for Stroop matching task interference. Psychology and Neuroscience, 3(2), 141-150.

MacLeod, C. M., \& MacDonald, P. A. (2000). Interdimensional interference in the Stroop effect: uncovering the cognitive and neural anatomy of attention. Trends in Cognitive Sciences, 4(10), 383-391.

Milham, M. P., Banich, M. T., Webb, A., Barad, V., Cohen, N. J., Wszalek, A. F., \& Kramer, A. F. (2001). The relative involvement of anterior cingulate and prefrontal cortex in attentional control depends on nature of conflict. Cognitive Brain Research, 12, 467-473.

Miller, E. K., \& Cohen, J. D. (2001). An integrative theory of prefrontal cortex function. Annual Review of Neuroscience, 24, 167-202.

Posner, M. I., \& Digirolamo, G. J. (1998). Executive attention: conflict, target detection, and cognitive control. In R. Parasuraman (Ed.). The attentive brain (pp. 401-423). Cambridge, MA: MIT Press.

Stroop, J. R. (1935). Studies of interference in serial verbal reactions. Journal of Experimental Psychology, 18(6), 643-662.

Sugg, M. J., \& McDonald, J. E. (1994). Time course of inhibition in color-response and word-response versions of the Stroop task. Journal of Experimental Psychology: Human Perception and Performance, 20(3), 647-675.

Treisman, A., \& Fearnley, S. (1969). The Stroop test: selective attention to colours and words. Nature, 222(5192), 437-439.

Virzi, R. A., \& Egeth, H. E. (1985). Toward a translational model of Stroop interference. Memory and Cognition, 13(4), 304-319.

Submissão: 18.6.2014

Aceitação: 18.8.2014 